\title{
Comparison of placental grading at different periods of gestation in PIH patients and their outcome
}

\author{
Sneha S. ${ }^{1 *}$, Sreelatha S. ${ }^{2}$, Renuka Ramaiah ${ }^{2}$
}

\begin{abstract}
${ }^{1}$ Department of Obstetrics and Gynecology, Sapthagiri Institute of Medical Sciences and Research Center, Bangalore, Karnataka, India

${ }^{2}$ Department of Obstetrics and Gynecology, ESIC and PGIMSR, Rajajinagar, Bangalore, Karnataka, India
\end{abstract}

Received: 15 September 2019

Accepted: 13 November 2019

*Correspondence:

Dr. Sneha S.,

E-mail: drsneharao@gmail.com

Copyright: () the author(s), publisher and licensee Medip Academy. This is an open-access article distributed under the terms of the Creative Commons Attribution Non-Commercial License, which permits unrestricted non-commercial use, distribution, and reproduction in any medium, provided the original work is properly cited.

\begin{abstract}
Background: The current study follows grannum grading of placenta. It is well known that there is accelerated placental maturation in PIH patients and the ultrasonic appearance of grade 3 placenta before 37 weeks may signify placental dysfunction and is associated with development of low birth weight babies, IUGR meconium stained liquor, low APGAR score. Hence this study was conducted to emphasize on placental grading at different periods of gestation to predict and prevent increased obstetric and fetal compromise and to compare the outcomes.

Methods: Obstetric scans were performed in all PIH patients attending antenatal OPD and inpatients at ESIC and PGIMSR medical college, Bangalore to know the placental grading and biophysical profile. These women were followed till their delivery for obstetric and fetal outcomes.

Results: Grade 3 placenta is seen in 17 patients in group 1(50\%) and 39 patients (59\%) in group 2. For statistical analysis grade 1 and 2 were combined and compared with grade 3. P-value 0.198 which was not statistically significant. There was no statistically significant difference in age and gravidity between two groups. The medical disorders were more in group 2 i.e., between 37 - 40 weeks. The complications of PIH were also more in group 2. There were more number of LSCS ( $n=19$ versus 14) in 34-36 weeks group which was not statistically significant. Fetal outcomes like IUGR and IUD were more in group 2 which was not statistically significant. The mean birth weight in group 1 was $2 \mathrm{~kg}$ as compared to $2.7 \mathrm{~kg}$ in group 2 . All associated medical disorders were more in group 2. Conclusions: In hypertensive women there is accelerated placental maturation leading to maternal and fetal complications. Hence women with accelerated placental maturity in ultrasound should be closely monitored and appropriately managed. However, we recommend larger randomized studies are necessary.
\end{abstract}

Keywords: Grannums study, Gestational age, PIH, Ultrasound placental grading

\section{INTRODUCTION}

Placenta is essential for the fetal wellbeing, growth and development which can be evidenced as early as possible through ultrasound at 6 weeks of gestation. ${ }^{1}$ Placenta mediates the intrauterine interaction between a mother and her baby. ${ }^{2}$ The association of ultrasonically detectable placental changes with increasing gestational age was first reported by Weinsberg et al, but it was Grannum et al who introduced a grading system based on ultrasonographic appearance of placentas. ${ }^{3,4}$ They graded placentas from 0 to 3 on the basis of changes in the appearance of chorionic plate, placental structure and basal layer. According to Petrucha and Piatt, all placenta starts as grade zero. ${ }^{5}$ The mean gestational age at which the placenta matures to grade 1 is 31.1 weeks, grade 2 
around 36.3 weeks, grade 3 around 38 weeks. By 38 weeks , 5 to $10 \%$ of placentas present as grade $3 .^{4,6}$ It was thought that Grannum grade 3 placenta was associated with mature fetal lung and placental dysfunction. ${ }^{7}$ In unselected population grade 3 placenta at or below 35 weeks gestation has been associated with subsequent development of preeclampsia and neonatal morbidity and mortality. ${ }^{8}$ Mckenna et al and Cooley et al demonstrated an association of accelerated placental maturation and maternal disease. ${ }^{9,10}$ This is further substantiated by other smaller studies. ${ }^{11} 10 \%$ of all pregnancies are complicated by PIH. PIH causes endothelial dysfunction and placental dysfunction and hence maternal and fetal complications. This study was undertaken to know the placental grading at 36 weeks so that appropriate measures can be taken to prevent complications.

\section{METHODS}

This is a prospective study done at ESIC and PGIMSR medical college Bangalore done from January 2016 to January 2017.Patients attending outpatient department of OBG and inpatient were included in the study. The institutional ethics committee approved the study. the inclusion criteria were all PIH patients (onset of high BP recording for the first time after 20 weeks gestation) who consented for the study were included.

Exclusion criteria was all chronic hypertension patients, patients with end organ damage.

The ultrasound examination was performed at 36 weeks gestation to determine placental maturity using phillips 2$5 \mathrm{MHz}$ transabdominal probe. Placental maturity and fetal biophysical profile were noted. Placental grading was determined using Grannum grading from 0 to 3 by noting the architecture of basal plate, chorionic plate, and placental substance.

- Grade 0 - placenta has an easily delineated straight chorionic plate and a homogenous texture throughout

- Grade 1 - placenta has undulating chorionic plate and scattered echogenic areas within

- Grade 2 - small echogenic areas in the placenta along the basal layer, comma like echogenic areas at the chorionic plate

- Grade 3 - echogenic indentations from chorionic plate to basal plate forming discrete cotylydons.

The studied pregnant women were allocated into two groups

- Group 1 - 34 to 36 weeks

- Group 2 - 37weeks - 40 weeks.

The two groups were compared for maternal age, parity, severity of hypertension, proteinuric or nonproteinuric, other medical risk factors, IUGR, mode of delivery and fetal weight, APGAR.

\section{Statistical analysis}

Data were analysed using software SPSS 20.Data were presented as frequency and percentage. $P$ value calculated as Chi-square test and $\mathrm{P} \leq 0.05$ was considered significant.

\section{RESULTS}

Grade 3 placenta is seen in 17 patients in group $1(50 \%)$ and in group 2 - 39 patients (59\%). For statistical analysis grade 1 and 2 were combined and compared with grade 3 . P-value 0.198 which was not statistically significant.

Table1: Comparison of placental grade between two groups.

\begin{tabular}{|lll|}
\hline Placental grade & $\mathbf{3 4 - 3 6}$ weeks & $37-40$ weeks \\
\hline Grade 1 & $\mathrm{~N}=5$ & 3 \\
\hline Grade 2 & $\mathrm{~N}=12$ & 24 \\
\hline Grade3 & $\mathrm{N}=17$ & 39 \\
\hline
\end{tabular}

Table 2: Comparison of gravidity between two groups.

\begin{tabular}{|ll|l|}
\hline Gravidity & $34-36$ weeks & $37-40$ weeks \\
\hline Primi & 20 & 29 \\
\hline Multi & 14 & 37 \\
\hline Total & $\mathbf{3 4}$ & $\mathbf{6 6}$ \\
\hline
\end{tabular}

There were more number of primigravida in 34-36 weeks group ( $n=20$ versus 14 ) compared to 37-40 weeks group which had more number of multigravida $(n=37$ versus 29). p value 0.158 which was not statistically significant.

Table 3: Comparison of age.

\begin{tabular}{|l|l|l|}
\hline Age & $34-36$ weeks & $37-40$ weeks \\
\hline 20-30 years & 19 & 45 \\
\hline $30-40$ years & 5 & 21 \\
\hline Total & $\mathbf{2 3}$ & $\mathbf{7 6}$ \\
\hline
\end{tabular}

There were more pregnant women between 20-30 years in both groups. $\mathrm{P}$ value was 0.309 which wasn't statistically significant. The medical disorders were more in group 2 i.e, between 37 - 40 weeks. The complications of PIH were also more in group 2.

There were more number of LSCS ( $n=19$ versus 14$)$ in 34 - 36 weeks group as compared to 37 - 40 weeks which had more number of vaginal deliveries $(n=36$ versus $30)$.p value 0.255 which was not statistically significant. There were more number of patients between 20-30 years in both groups. There were 32 patients with mild PIH in group 2 compared to 18 patients in group 1, 18 patients with severe PIH in group 2 compared with 9 in group 1 . Eclampsia was seen in 8 patients in group 2 but none in 
group 1, abruption in 4 patients in group 2 but only one in group 1, IUD in 1 patient in group 2 none in group 1 . All associated medical disorders were more in group 2.

Table 4: Comparison of medical and obstetrical outcomes.

\begin{tabular}{|lll|}
\hline Outcome & $34-36$ weeks & $37-40$ weeks \\
\hline Previous LSCS & $\mathrm{N}=9$ & 11 \\
\hline Oligohydramnios & 4 & 4 \\
\hline IUGR & 4 & 7 \\
\hline Mild PIH & 18 & 32 \\
\hline Severe PIH & 9 & 18 \\
\hline Eclampsia & 0 & 8 \\
\hline HELLP & 7 & 8 \\
\hline Abruption & 1 & 4 \\
\hline Anemia & 1 & 3 \\
\hline GDM & 2 & 7 \\
\hline Hypothyroid & 7 & 10 \\
\hline IUD & 0 & 1 \\
\hline Rh negative & 0 & 5 \\
\hline
\end{tabular}

Table 5: Comparison of modes of delivery.

\begin{tabular}{|lll|}
\hline Mode of delivery & $34-36$ weeks & $37-40$ weeks \\
\hline LSCS & 19 & 30 \\
\hline Vaginal delivery & 14 & 36 \\
\hline
\end{tabular}

\section{DISCUSSION}

The placenta mediates the intrauterine interaction between a mother and her baby, it is directly responsible for mediating maternal environment necessary for fetal development. $^{2}$

As the placenta ages, it begins to thin and in third trimester may calcify. In approximate $15 \%$ cases the calcifications extend completely through the substance of the placenta, completely outlining the cotyledons. These are termed grade 3 changes and should not occur before 34 weeks. ${ }^{12}$ This study observed grade 3 placenta in more number of young primigravida patients in both groups as compared to multigravida which is comparable to study by Mc Kenna et al. ${ }^{9,13}$ Premature placental maturation to a grade 3 configuration has been found in patients with chronic hypertension, preeclampsia, IUGR ${ }^{14,15}$ Grannum and Hobbins stated that finding of grade 3 placenta before 35 weeks may preceed the diagnosis of preeclampsia, IUGR and should prompt close follow up of the patient for the between duration and pregnancy. ${ }^{4}$ Grade 3 placenta remote from term is associated with fetal death, IUGR, fetal distress and meconium staining of liquor. ${ }^{16}$ A recent study by cooley et al in 2010 suggested that higher granum grades were associated with increase in incidence of preeclampsia, obstetric intervention, SGA infants. ${ }^{11}$ Placental grading has been used to predict an increased antepartum risk and can be used in evaluating fetuses at risk for intrauterine growth retardation. ${ }^{17} \mathrm{Mc}$ Kenna et al suggested that ultrasound detection of grade 3 placenta in low risk population at 36 weeks may identify a subgroup of women at risk for developing proteinuric PIH in later stages of pregnancy and to have their labour induced for suspected fetal compromise. $^{9}$

\section{CONCLUSION}

In hypertensive women there is accelerated placental maturation leading to maternal and fetal complications. Hence women with accelerated placental maturity in ultrasound should be closely monitored and appropriately managed. However, we suggest larger randomized studies are required.

\section{Funding: No funding sources}

Conflict of interest: None declared

Ethical approval: The study was approved by the Institutional Ethics Committee

\section{REFERENCES}

1. Palmer PES. Obstetrics. In: Palmer PES(ed) Manual of diagnostic ultrasound, WHO Library Catologuing in Publication Data. 2003:223-82.

2. Collins S, Arulkumaran S, Hayes S, Jackson S, Impey L. Normal pregnancy. In: Collins, Arulkumaran, Hayes, Jackson, Impey (eds .) Oxford Handbook of Obstetrics and Gynecology, $2^{\text {nd }}$ edition, Oxford University Press. 2008:1-46.

3. Weinsberg F. Echographic changes with placental aging. J Clin Ultrasound. 1973;1:52-60.

4. Grannum PAT, Berkowitz RL, Hobbins JC. The ultrasonic changes in the maturating placenta and their relation to fetal pulmonic maturity. Am J Obstet Gynecol. 1979;133:915-22.

5. Petrucha RA, Piatt LD. Relationship of placental grade to gestational age. Am J Obstet and Gynecol. 1982;144:733-35.

6. Grannum PA, Hobbins JC. The placenta. Radiol Clin North Am. 1982;20:353-65.

7. Chudleigh T, Thilaganathan B. The placenta and amniotic fluid. In: Chudleigh, Thilaganathan(eds) Obstetric Ulrasound: How, Why and When, $3^{\text {rd }}$ edition, Elsevier Churchill Livingstone. 2004:9137-47.

8. Carrol B. Ultrasonic features of preeclampsia. J Clic Ultrasound. 1980;8:483-88.

9. Mc Kenna D, Tharamarathnam S, Mahsud S, Dornan J. Ultrasounnic evidence of placental calcification at 36 weeks gestation: maternal and fetal outcomes. Acta Obstet Gynecol Scand. 2005;84:7-10.

10. Cooley SM, Donnelly JC, Walsh T, McMohan c, Gillan J, Geary MP. The impact of ultrasonographic placental architecture on antenatal course, labour and delivery in a low risk primigravid population. J Mater Fetal Neonatal Med. 2010;7:1-5.

11. Valenzuela BA, Méndez GA. Premature aging of the placenta, ultrasonic diagnosis. Ginecol Obstet Mex. 1995;63:287-92. 
12. Middleton WD, Kurtz AB, Hertzberg BS. Fetal growth and wellbeing. In: Middleton, Kurtz, Hertzberg (eds) Ultrasound: The Requisites ,2 $2^{\text {nd }}$ edition. Mosby. 2004:330-41.

13. Brown HL, Miller JM, Khawli O, Gabert HA. Premature placental calcification in maternal cigarette smokers. Obstet Gynecol. 1988;71:914-17.

14. Kazzi GM, Gross TL, Sokol RJ, Kazzi NJ. Detection of intrauterine growth retardation : a new use for sonographic placental grading. Am J Obstet Gynecol. 1983;145:733-37.

15. Merz E. The placenta, umblical cord, and amniotic fluid. In: Merz E (ed). Ultrasound in Gynecology and Obstetrics: Textbook and atlas, Thieme Medical Publishers. 1991:232-248.

16. Alkazaleh F, Viero S kingdom JCP. Sonographic evaluation of the placenta. In: Rumack, Wilson,
Charboneau, Johnson (eds.) Diagnostic ultrasound. $3^{\text {rd }}$ edition. Obstetric and fetal sonography. Elsevier Mosby. 2005:1557-81.

17. Callan NA. Intrauterine growth retardation. In: Quilligan , Zuspan (eds) Current therapy in Obstetrics and Gynecology, $5^{\text {th }}$ edition, Philadelphia: WB Saunders. 2000:307-310.

Cite this article as: Sneha S., Sreelatha S., Ramaiah R. Comparison of placental grading at different periods of gestation in PIH patients and their outcome. Int J Reprod Contracept Obstet Gynecol 2019;8:4747-50. 